\title{
Dissociable Effects of Antipsychotics on Ketamine-Induced Changes in Regional Oxygenation and Inter-Regional Coherence of Low Frequency Oxygen Fluctuations in the Rat
}

\author{
Jennifer Li*,1,4, Keita Ishiwari ${ }^{1,2,4}$, Michael W Conway', Jennifer Francois', John Huxter', John P Lowry², \\ Adam J Schwarz ${ }^{3}$, Mark Tricklebank' and Gary Gilmour' \\ 'Centre for Cognitive Neuroscience, Eli Lilly and Co. Limited, Windlesham, Surrey, UK; '²Department of Chemistry, National University of Ireland, \\ Maynooth, Co. Kildare, Ireland; ${ }^{3}$ Tailored Therapeutics, Eli Lilly and Company, Indianapolis, IN, USA
}

\begin{abstract}
Typical and atypical antipsychotics have been shown to alleviate N-methyl-D-aspartate (NMDA) receptor antagonist-induced BOLD signals in healthy humans and animals to differing degrees; factors that might relate to their different molecular mechanisms and clinical profiles. Recent studies have also extended these investigations to the analysis of resting state functional connectivity measures of BOLD signals in different brain regions. Using constant potential amperometry, we examined the effects of the NMDA receptor antagonist $\mathrm{S}-(+)$-ketamine on tissue oxygen levels in medial prefrontal cortex (mPFC) and medial ventral striatum (mVS), and temporal coherence of low-frequency oxygen fluctuations between these regions in freely moving rats. Furthermore, we assessed the extent to which the

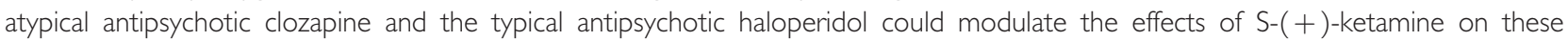
measures. Acute S- $(+)$-ketamine $(5-25 \mathrm{mg} / \mathrm{kg})$ produced dose-dependent increases in both tissue $\mathrm{O}_{2}$ levels and coherence. Although effects of clozapine and haloperidol alone were relatively minor, their effects on ketamine-induced signals were markedly more distinct. Clozapine dose-dependently attenuated the absolute $\mathrm{S}-(+)$-ketamine $(25 \mathrm{mg} / \mathrm{kg}) \mathrm{O}_{2}$ signal in both regions, and also attenuated ketamine-induced increases in regional coherence. Haloperidol had no effect on the absolute ketamine $\mathrm{O}_{2}$ signal yet potentiated increases in regional coherence. The dissociable effects of haloperidol and clozapine on ketamine-induced hyperoxygenation and mPFCmVS coherence elucidate potentially important mechanistic differences between these classes of pharmacology. This study demonstrates for the first time that in vivo amperometry can measure both regional brain tissue $\mathrm{O}_{2}$ levels and inter-regional coherence, advancing BOLD-like measurements of functional connectivity into awake, unconstrained animals.

Neuropsychopharmacology (2014) 39, 1635-1644; doi: I0.1038/npp.20 I4.10; published online 12 February 2014
\end{abstract}

Keywords: constant potential amperometry; brain tissue oxygen; functional connectivity; coherence; ketamine; antipsychotics

\section{INTRODUCTION}

Brain imaging techniques have had substantial impact on neuroscience, for example, by highlighting regional and systems-level dysfunction of brain circuitry in neuropsychiatric disease. Pharmacological magnetic resonance imaging (phMRI) responses are widely used to probe disease-related pharmacology, for example, N-methyl-Daspartate (NMDA) antagonist-induced brain activation as a model of schizophrenia and its modulation by antipsychotics (eg, Gozzi et al, 2008; Chin et al, 2011; Doyle et al, 2013). However, in this context, several studies have suggested that modulation of NMDA antagonist imaging signals by antipsychotics does not necessarily concur with

\footnotetext{
*Correspondence: Dr J Li, Lilly Centre for Cognitive Neuroscience, Eli Lilly \& Co. Ltd, Erl Wood Manor, Windlesham, Surrey GU20 6PH, UK, Tel: +44 1276 483472, Fax: +44 1276 483525, E-mail: lije@lilly.com ${ }^{4}$ These authors contributed equally to this work. Received 30 August 2013; revised 13 January 2014; accepted 14 January 2014; accepted article preview online 20 January 2014
}

their effects on 'psychotic' symptoms (eg, Lahti et al 1995, Malhotra et al, 1996). Recently, novel imaging paradigms have shifted their focus to assessment of intrinsic brain activity to complement studies of evoked or event-related activity (Biswal et al, 1995; Fox and Raichle, 2007). Such studies have explored the notion of functional connectivity between brain regions using low-frequency BOLD fluctuation correlations, and abnormalities have been identified in resting-state connectivity in numerous diseases, including schizophrenia (for review, see Fox and Greicius, 2010). Assessment of functional connectivity via functional MRI (fMRI) in rodents is possible but is presently limited to anesthetized or heavily restrained animals (see review by Ferris et al, 2011), greatly limiting the scope of behavioral studies.

In-vivo oxygen amperometry is an alternative to rodent fMRI that can measure real-time changes in extracellular oxygen $\left(\mathrm{O}_{2}\right)$ in freely moving animals. This technique has been successfully used to measure regional brain tissue $\mathrm{O}_{2}$ levels with sub-second temporal resolution in a variety of behavioral paradigms (McHugh et al, 2013; Francois et al, 
2012; Howe et al 2013). Amperometric $\mathrm{O}_{2}$ signals have been shown to be analogous to the fMRI BOLD signal (Lowry et al, 2010) and functionally related to discrete neuronal activation events ( $\mathrm{Li}$ et al, 2011). Tissue $\mathrm{O}_{2}$ signals also display low-frequency fluctuations similar to the BOLD signal, raising the possibility that analyses analogous to functional connectivity fMRI methods might be conducted in the conscious, behaving rodent by measuring correlations in these fluctuations between different brain areas.

Identification of resting-state networks and descriptions of their modification and dysfunction in disease states have encouraged cross-species study of pharmacological modulation of regional functional connectivity (Zhu et al, 2013; Gass et al, 2013), notably in the context of translational biomarkers of psychosis and antipsychotic efficacy. In this regard, the uncompetitive NMDA receptor antagonist ketamine (Anis et al, 1983; Lodge and Johnson, 1990) can be used in humans and animals to induce behavioral change bearing resemblance to psychosis (eg, Krystal et al, 1994; Malhotra et al, 1996, Moghaddam et al, 1997) that, in humans at least, concomitantly changes regional brain activity and coherence across different resting state networks. However, to date, there have been no studies looking at the effect of antipsychotics on ketamine-induced changes in functional connectivity in either species, hence both preclinical and clinical studies are needed to allow a translational mapping of cross-species effects. The aim of this study was to apply rat in vivo $\mathrm{O}_{2}$ amperometry to allow simultaneous assessment of antipsychotic-induced modulation of S- $(+)$-ketamine-induced changes in prefrontal and ventral striatal regional activity and coherence, regions implicated in psychosis (Duncan et al, 1998b).

\section{MATERIALS AND METHODS}

\section{Subjects}

All experiments were conducted in accordance with the Animals (Scientific Procedures) Act 1986 and local ethical requirements of Eli Lilly. Twenty-two male Lister Hooded rats (300-400 g at surgery; Harlan, UK) were group-housed in a temperature-controlled $\left(20-22{ }^{\circ} \mathrm{C}\right)$ environment with food and water available ad libitum under a 12-h light/12-h dark cycle for at least 7 days prior to surgical preparation. Following surgery, animals were singly housed under similar environmental conditions.

\section{In Vivo Amperometry}

Changes in extracellular tissue $\left[\mathrm{O}_{2}\right]$ were measured using constant potential amperometry with carbon paste electrodes (CPEs) (Lowry et al, 1997). A potential of $-650 \mathrm{mV}$ was applied to electrodes allowing the electrochemical reduction of dissolved $\mathrm{O}_{2}$ at their tip (Lowry et al, 1996; Bolger et al, 2011). CPEs were constructed from $8 \mathrm{~T}(200 \mu \mathrm{m}$ bare diameter, $270 \mu \mathrm{m}$ coated diameter) Teflon-coated silver wire (Advent Research Materials, Suffolk, UK). The Teflon insulation was slid along the wire to create an $\sim 2-\mathrm{mm}$ deep cavity, which was packed with carbon paste (prepared according to O'Neill et al, 1982). Prior to implantation, all CPEs were calibrated in vitro in a glass cell containing $15 \mathrm{ml}$ phosphate buffer solution $(0.01 \mathrm{M}), \mathrm{pH} 7.4$, saturated with nitrogen $\left(\mathrm{N}_{2}\right)$ gas, atmospheric air (from a RENA air pump), or pure $\mathrm{O}_{2}$ (compressed gas) at room temperature. The concentrations of dissolved $\mathrm{O}_{2}$ were taken as $0 \mu \mathrm{M}\left(\mathrm{N}_{2}\right.$ saturated), $240 \mu \mathrm{M}$ (air-saturated) (Foster et al, 1993), and $1260 \mu \mathrm{M}\left(\mathrm{O}_{2}\right.$-saturated) (Bourdillon et al, 1982), respectively. Reference and auxiliary electrodes were also prepared from $8 \mathrm{~T}$ Teflon-coated silver wire by removing $2 \mathrm{~mm}$ Teflon from the tip. All electrodes were soldered to gold connectors, which were cemented into six-pin plastic sockets (both from Plastic One, Roanoke, VA) during surgery.

\section{Surgery}

Under isoflurane anesthesia, animals were implanted bilaterally with CPEs in the medial prefrontal cortex (mPFC) (AP: $+3.2 \mathrm{~mm}$; ML: $\pm 0.7 \mathrm{~mm}$; DV: $-4.2 \mathrm{~mm}$ from dura) and the medial ventral striatum (mVS) (AP: $+1.9 \mathrm{~mm}$; ML: $\pm 0.8 \mathrm{~mm}$; DV: $-6.9 \mathrm{~mm}$ from dura). The reference electrode was placed in posterior cortex, and the auxiliary electrode was wrapped around one posterior skull screw. Preand post-operative Rimadyl (Carprofen $5 \mathrm{mg} / \mathrm{kg} \mathrm{sc}$; Pfizer) was administered, and animals were allowed to recover in thermostatically controlled cages. A post-operative period of 2 weeks was allowed before testing commenced.

\section{Drugs}

(S)-(+ )-ketamine hydrochloride (Sigma-Aldrich, Gillingham, UK) was dissolved in $0.9 \%(\mathrm{w} / \mathrm{v})$ saline, clozapine (SigmaAldrich) in a $50: 50 \mathrm{mix}$ of $0.1 \mathrm{M} \mathrm{HCl}$ and $0.9 \%(\mathrm{w} / \mathrm{v})$ saline, and haloperidol (Tocris, Bristol, UK) initially in $1 \mathrm{M}$ lactic acid ( $10 \%$ of total required) and brought up to volume with $0.9 \%(\mathrm{w} / \mathrm{v})$ saline.

\section{Testing Schedule}

Animals were tested in Perspex test chambers $(40 \times 40 \times 40$ $\mathrm{cm})$, where their head mounted six-pin socket was connected to a low-noise, four-channel potentiostat (Biostat, ACM Instruments, Cumbria, UK) via a flexible screened six-core cable mounted through a swivel (both Plastics One Roanoke, VA) in the ceiling of the cage. This arrangement allowed free movement of the animal throughout the cage. One hour before dosing, animals were placed individually in test chambers and a constant $-650 \mathrm{mV}$ potential applied to CPEs to allow signal settling. Both haloperidol $(0.25,0.5,1 \mathrm{mg} / \mathrm{kg}$ ip) and clozapine $(5,10$, $20 \mathrm{mg} / \mathrm{kg}$ ip) were dosed $30 \mathrm{~min}$ before injection of $25 \mathrm{mg} / \mathrm{kg}$ ketamine sc. Signals were recorded for $2 \mathrm{~h}$ after ketamine dosing, following which animals were returned to their home cages. Animals in each cohort randomly received each treatment condition per study, allowing at least 1 week between test sessions.

\section{Data Recording and Processing}

Amperometric recordings from each working electrode channel were recorded at $40 \mathrm{~Hz}$, and a PowerLab 8/30 was used for analog/digital conversion before data were collected on a PC running Chart v5 (both AD Instruments, Oxford, UK). For each brain region ( $\mathrm{mVS}$ and $\mathrm{mPFC}$ ), one 
hemisphere was chosen from each animal to be included in the analysis, which was determined based on visual inspection of noise level and signal quality. Post-collection, linear interpolation was used to replace occasional missing data points and a bi-quad Butterworth filter (high-pass $0.1 \mathrm{~Hz}$ ) was used to suppress fast noise-related artifacts. Data were normalized by subtraction of the $60 \mathrm{~s}$ average pre-dose value from each data point in the series, thereby compensating for absolute differences in baselines between channels. Finally, a boxcar-averaging algorithm was applied to down-sample the data, keeping a single average from multiple $120 \mathrm{~s}$ non-overlapping windows.

\section{Data Analysis}

With regard to absolute regional signals, data were analyzed for $6800 \mathrm{~s}$ post-injection for the ketamine dose response study and $3600 \mathrm{~s}$ for all other studies. The full time course was shown for the ketamine dose response to show the time taken for the response to return to baseline levels, but given the peak of the response occurs within the first hour, all studies looking at the modulation of the ketamine response just shows the first $60 \mathrm{~min}$. Area under the curve (AUC) was calculated according to the formula $\mathrm{AUC}=\left(\sum_{t-0}^{n} a * d\right)$ where $n=$ number of samples in the curve, $a=$ current (nA) at a given sample and $d=$ sample interval (120s). For all studies, regional coherence data were analyzed in the $0.01-$ $0.1 \mathrm{~Hz}$ range, from a period $300 \mathrm{~s}$ pre-dose to $1800 \mathrm{~s}$ postdose, and averaged in $300 \mathrm{~s}$ time bins. To achieve this, the injection-aligned series of $N$ data points from both brain regions were padded with $\mathrm{N} / 4$ additional points such that data trended toward zero rate of change. Padding helps to eliminate edge-artifacts which are produced when applying a low-pass filter to data with a mean offset from zero. Butterworth noise filtering was applied as before for each frequency $F$ of interest and then data were correlated in a series of half-overlapping windows of length $2 / \mathrm{F}$, excluding padded sections of data. Pearson's $r$ was generated as an index of coherence between the filtered signals at a given time for that frequency, to build a coherence spectrum over time for multiple frequency bins.

For absolute regional $\left[\mathrm{O}_{2}\right]$ levels, AUC values were analyzed by a repeated measures ANOVA followed by Fisher's LSD post hoc test for multiple comparisons. For coherence analysis, broadband $(0.1-0.01 \mathrm{~Hz})$ correlation values (Pearson's $r$ ) were binned into $5 \mathrm{~min}$ time blocks, with one pre-dose time bin and six post-dose time bins. All $r$-values underwent Fisher's $z$-transformation before repeated measures ANOVA with treatment group and timebin as within-subjects factors was performed. This is followed by Fisher's LSD post hoc test for multiple comparisons. Mauchly's sphericity test was performed on all coherence data and Greenhouse-Geisser adjustments applied to degrees of freedom as necessary.

\section{Histology}

Animals were deeply anaesthetized with pentobarbital and perfused transcardially with $0.9 \%(\mathrm{w} / \mathrm{v})$ saline followed by $10 \%(w / v)$ buffered paraformaldehyde solution. Brains were removed and placed in $10 \%(\mathrm{w} / \mathrm{v})$ buffered paraformaldehyde and shipped for histological processing (Neuroscience
Associates, Knoxville, TN), which involved $40 \mu \mathrm{m}$ coronal sectioning of implanted regions and staining with thionin for Nissl bodies. Upon return, microscopic assessment confirmed CPE placement with reference to a standard rat brain atlas (Paxinos and Watson, 2009). All inaccurate placements were excluded from subsequent analyses. The nucleus accumbans shell/core placements were pooled due to the low number of animals and lack of power to make a separate assessment. For coherence analysis, only animals with correctly placed electrodes and noise-free signals in both brain regions were included.

\section{RESULTS}

\section{Histology}

Figure 1 depicts photomicrographs of representative electrode placements in mPFC (Figure 1a) and mVS (Figure 1b), and reconstruction of all electrode placements (Figure 1c).

\section{S-(+)-Ketamine dose Response Study}

As shown in Figure 2, ketamine produced robust, dosedependent increases in tissue $\left[\mathrm{O}_{2}\right]$ in both regions as confirmed by significant main effects of dose on the AUC measure (mPFC: $\mathrm{F}_{(3,21)}=20.7, p<0.001 ; \mathrm{mVS}: \mathrm{F}_{(3,15)}=37.4$, $p<0.001)$. All doses of ketamine induced significant increases in AUC relative to the vehicle control (Figure $2 \mathrm{~b}$ and $\mathrm{d}$ ). In both regions, peak $\left[\mathrm{O}_{2}\right]$ levels occurred within $6 \mathrm{~min}$ of dosing and higher doses produced progressively more sustained increases in $\left[\mathrm{O}_{2}\right]$.

Figure 2e depicts coherograms of correlation strength across the $0.01-0.1 \mathrm{~Hz}$ range from $-300 \mathrm{~s}$ to $1800 \mathrm{~s}$ postinjection for all treatment groups. Both time and dosedependent changes in regional coherence are clearly evident from this figure. This data is summarized in figure $2 \mathrm{f}$, where an averaged correlation of the frequency range of interest $(0.01-0.1 \mathrm{~Hz})$ for each treatment group is depicted in $5 \mathrm{~min}$ time bins. Following a Greenhouse-Geisser adjustment, a main effect of time $\left(\mathrm{F}_{(3.3,23.2)}=3.07, p=0.044\right)$ and post hoc analyses revealed a significant increase in coherence in the $10 \mathrm{mg} / \mathrm{kg} \mathrm{S}-(+)$-ketamine group between 5 and $25 \mathrm{~min}$, and in the $25 \mathrm{mg} / \mathrm{kg} \mathrm{S}-(+)$-ketamine group between 5 and 15 min post-injection compared with the 5 min pre-injection baseline.

\section{Clozapine and Haloperidol dose Response Studies}

Clozapine caused a slight but significant attenuation of $\left[\mathrm{O}_{2}\right]$ AUC in the $\mathrm{mPFC}$ (Figure 3a), where a significant main effect of dose was found $\left(\mathrm{F}_{(3,15)}=3.91, p=0.03\right)$, but not in the mVS (Figure $3 \mathrm{~b}$ ). Following post-hoc comparisons, all doses of clozapine were found to significantly decrease AUC relative to the vehicle control (all $p<0.05$ ) in the mPFC. With regard to summarized regional coherence (Figure $3 c$ ), clozapine had little effect. The summarized data showed a significant main effect of time $\left(\mathrm{F}_{(6,12)}=3.58, p=0.029\right)$, but post hoc comparisons revealed only the $10 \mathrm{mg} / \mathrm{kg}$ clozapine group showed significant decreases in coherence at the $15-25 \mathrm{~min}$ time points relative to the pre-injection baseline $(p<0.05)$. 

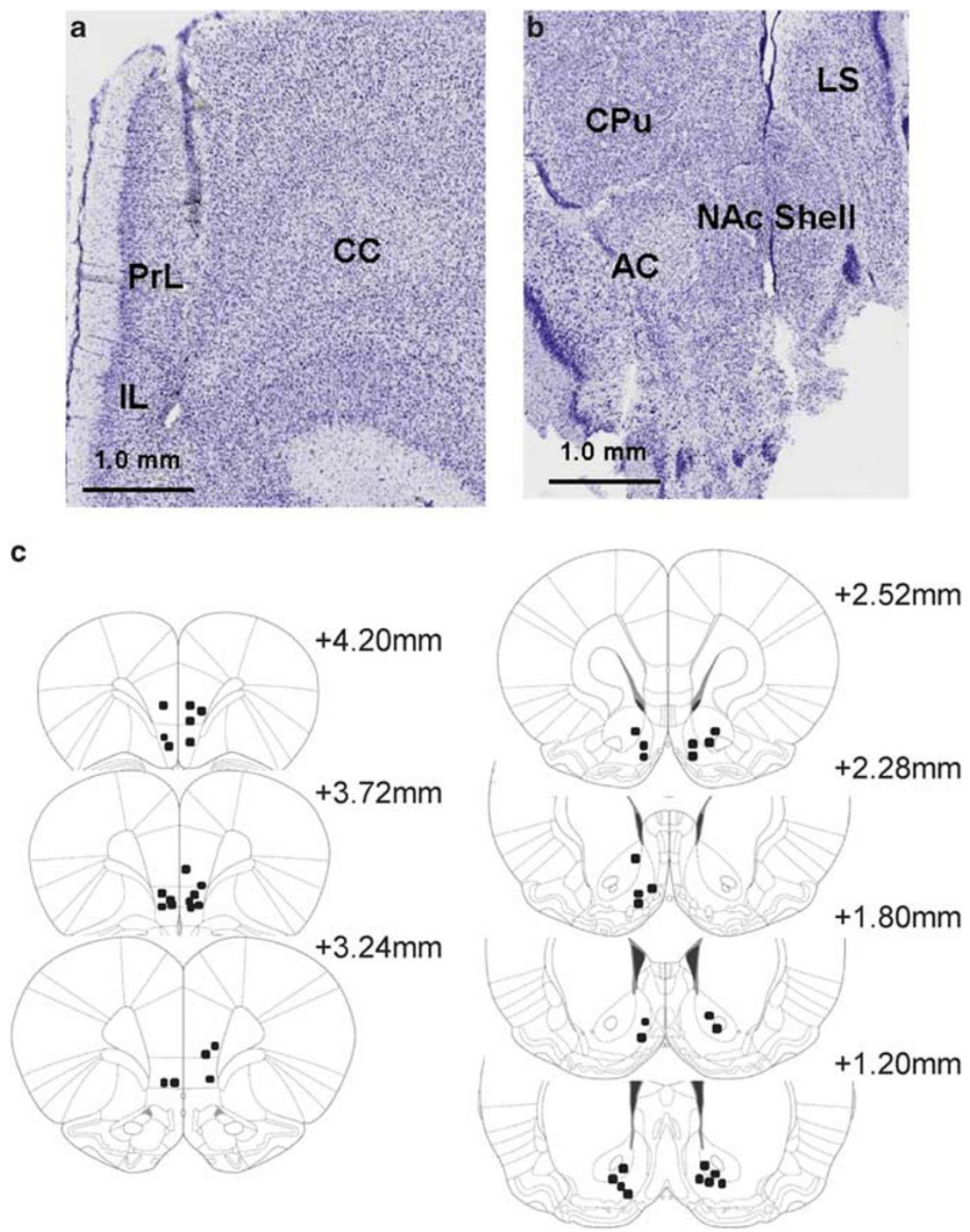

Figure I CPE placements. Photomicrographs of Nissl-stained sections showing the locus surrounding representative electrode placements in (a) medial prefrontal cortex and (b) ventromedial striatum. Scale bar, $1.0 \mathrm{~mm}$. (c) Reconstruction of all electrode tip placements in medial prefrontal cortex and ventromedial striatum. Abbreviations: PrL, prelimbic cortex; IL, infralimbic cortex; CC, corpus callosum; NAc, nucleus accumbens; CPu, caudate putamen; LS, lateral septum; AC, anterior commissure. Figure generated from the Paxinos and Watson (2009) rat brain atlas.

AUC analyses showed significant effects of haloperidol dose in both regions (mPFC: $\mathrm{F}_{(3,18)}=3.45, p=0.038$; mVS: $\left.\mathrm{F}_{(3,15)}=3.97, p=0.029\right)$ where the $0.25 \mathrm{mg} / \mathrm{kg}$ dose significantly increased AUC in both regions compared with vehicle $(p<0.01)$ (Figure 3, lower panel). Similarly to clozapine, haloperidol also had little effect on regional $\left[\mathrm{O}_{2}\right]$ coherence (Figure 3f), with only a trend toward a significant main effect of time following repeated measures ANOVA $\left(\mathrm{F}_{(6,42)}=2.16, p=0.066\right)$ observed $(n=8)$.

\section{Clozapine-S- $(+)$-Ketamine Interaction Study}

Time course data (Figure 4a and c) show that clozapine dose-dependently attenuated ketamine-induced increases in $\left[\mathrm{O}_{2}\right]$ in both brain regions. This is confirmed by the AUC analysis which revealed a significant dose effect in the $\operatorname{mPFC}\left(\mathrm{F}_{(3,15)}=32.86, p<0.001\right)$, where clozapine dosedependently and significantly reduced $\left[\mathrm{O}_{2}\right]$ at all doses tested (Figure $4 \mathrm{~b}$ ). In mVS, there was a trend toward an effect of dose $\left(\mathrm{F}_{(3,12)}=3.44, p=0.05\right)$, where $20 \mathrm{mg} / \mathrm{kg}$ of clozapine significantly reduced $\left[\mathrm{O}_{2}\right]$ AUC relative to ketamine alone in a post hoc comparison (Figure $4 \mathrm{~d}$ ). Frequency range $\times$ time coherograms of ketamine for this study (Figure 4e) looked similar to those as observed in the ketamine dose response study, whereby increased regional $\left[\mathrm{O}_{2}\right]$ coherence following ketamine treatment is evident. Thirty minutes pre-treatment with clozapine dose-dependently reduced this increase in $\left[\mathrm{O}_{2}\right]$ coherence caused by ketamine, shown by the prominence of colder colors particularly in the 10 and $20 \mathrm{mg} / \mathrm{kg}$ clozapine-treated groups. These data are summarized in Figure $4 \mathrm{f}(n=6)$. Following a significant dose $\times$ time interaction $\left(\mathrm{F}_{(18,90)}=2.44, p=0.003\right)$ here, post hoc analyses first revealed a significant increase in coherence in the Veh/ket group between 5-20 min and 25-30 min post-injection, and also in the $5 /$ Ket group at the $5-15$ min post-injection time points compared with the $5 \mathrm{~min}$ pre-injection baseline ( $-5-0 \mathrm{~min}$ ) (all $p<0.05)$. The $20 \mathrm{mg} / \mathrm{kg}$ dose of clozapine 

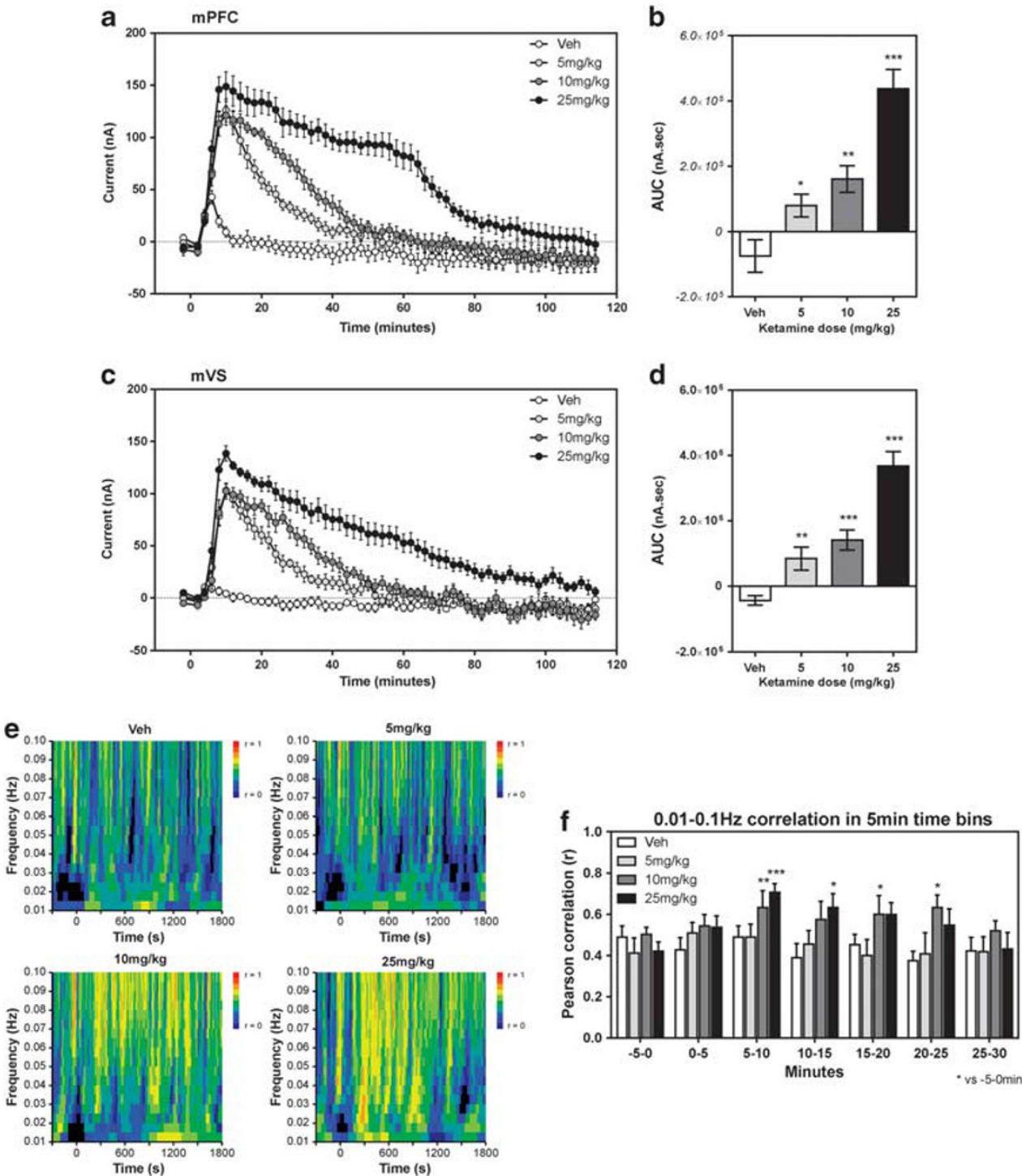

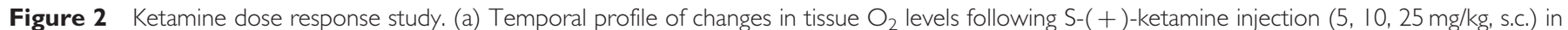
$\operatorname{mPFC}(n=8)$ and $(c)$ mVS $(n=6)$. Means $\left( \pm\right.$ SEM) of normalized $\mathrm{O}_{2}$ currents averaged over 2-min time bins are shown for the 2-h post-injection period. (b) mPFC and (d) mVS AUC measures extracted from the $\mathrm{O}_{2}$ response, where bars represent mean ( \pm SEM) AUC for the 2-h period following S- $(+)$ ketamine injection. ${ }^{*} p<0.05$, $* * 0.01$, *** $p<0.00$ I vs vehicle. (e) Coherograms for each treatment group showing the correlation value ( $r$ ) by color intensity at frequencies between 0.01 and $0.1 \mathrm{~Hz}$ (Y-axis) for -300 s pre-injection to 1800 s post-injection on the $X$-axis. (f) Summary of coherence data showing the correlation of the whole frequency range $(0.0 \mathrm{I}-0.1 \mathrm{~Hz})$ for each treatment group in 5 min time bins $(n=8)$. Bars represent mean $( \pm \mathrm{SEM})$ Pearson correlation values $(r)$ between 0.01 and $0.1 \mathrm{~Hz}$ in $5 \mathrm{~min}$ time blocks. RMANOVA performed on Fisher transformed $r$-values, and values quoted after a Greenhouse-Geisser correction. $* p<0.05$, ** $p<0.01$, *** $p<0.001$ vs pre-injection baseline.

also showed a statistically significant decrease in coherence relative to the $5 \mathrm{~min}$ pre-injection baseline $(-5-0 \mathrm{~min})$ at $15-30$ min time points (all $p<0.05)$. Compared with the Veh/Ket group, the $5 \mathrm{mg} / \mathrm{kg}$ dose of clozapine attenuated the ketamine coherence increase at the $15-25$ min time points (both $p<0.05$ ), whereas at doses of $10 \mathrm{mg} / \mathrm{kg}$ and $20 \mathrm{mg} / \mathrm{kg}$ clozapine pre-treatment significantly reduced ketamineinduced regional $\left[\mathrm{O}_{2}\right]$ coherence increases for the $5-30 \mathrm{~min}$ time points inclusive (all $p<0.01$ ).

\section{Haloperidol-S- $(+)$-Ketamine Interaction Study}

Time course data (Figure 5a and c) show that haloperidol pre-treatment had little effect on the ketamine response in both brain regions, and the AUC analyses for both regions (Figure $5 \mathrm{~b}$ and $\mathrm{d}$ ) revealed no significant effects following pre-treatment with haloperidol on ketamine-induced increases in regional $\left[\mathrm{O}_{2}\right]($ all $\mathrm{F}<4)$. Frequency range $\times$ time coherograms (Figure 5e) confirmed a similar effect of ketamine alone to that observed in the ketamine dose response study with increases in regional $\left[\mathrm{O}_{2}\right]$ coherence observed following ketamine administration, but in this case haloperidol appeared to further increase coherence rather than decrease it. This was confirmed statistically in the summary analysis of coherence, as depicted in Figure $5 f$ $(n=7)$. Repeated-measures ANOVA showed a significant main effect of dose $\left(\mathrm{F}_{(3,18)}=3.50, p=0.037\right)$ and time $\left(\mathrm{F}_{(6,36)}=14.25, p<0.001\right)$ but no dose $\times$ time interaction 

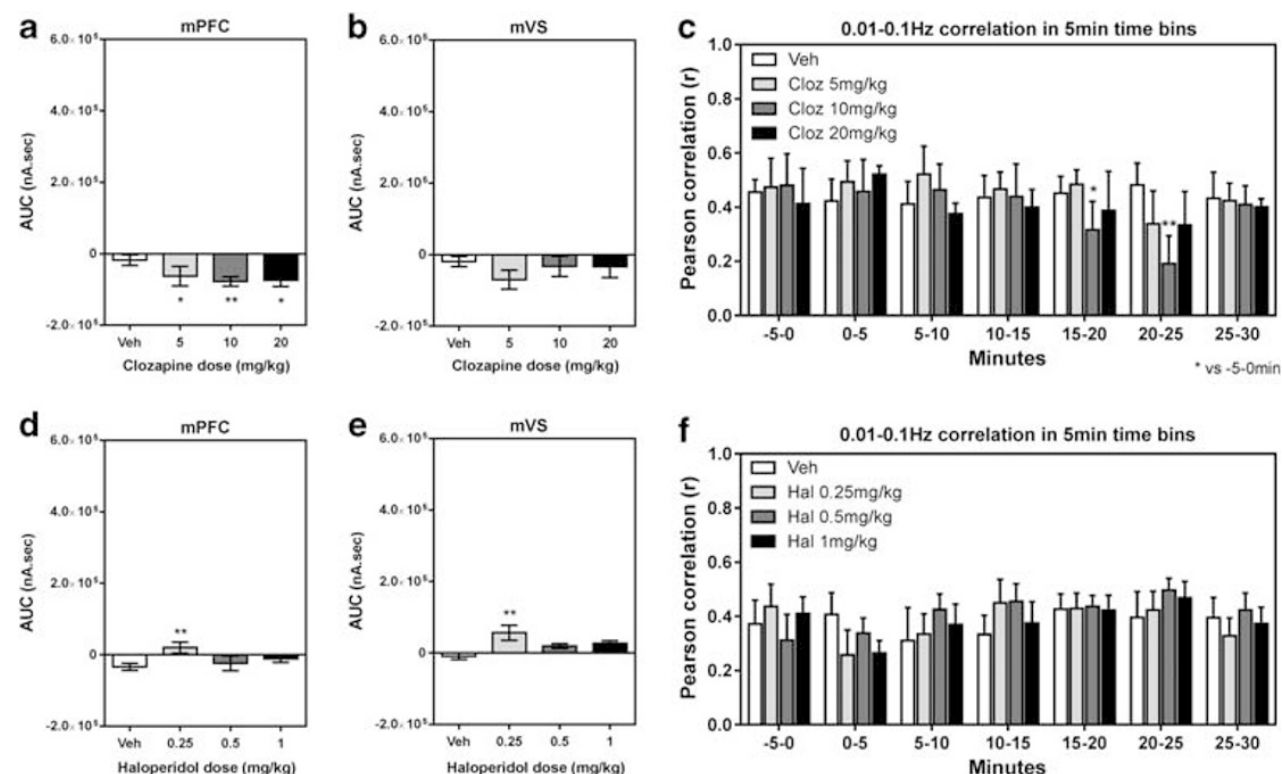

Figure 3 Clozapine and haloperidol dose response studies. Effect of clozapine injection (5, 10, $20 \mathrm{mg} / \mathrm{kg}$, i.p.) on (a) mPFC ( $n=6)$ and (b) $\mathrm{mVS}(n=6)$ AUC measures extracted from the $\mathrm{O}_{2}$ response, where bars represent mean ( \pm SEM) AUC for the I-h period following clozapine injection. (c) Summary of coherence data showing the correlation of the whole frequency range $(0.0 \mathrm{I}-0.1 \mathrm{~Hz})$ for each treatment group in $5 \mathrm{~min}(300 \mathrm{~s})$ time bins $(n=5)$. Bars represent mean ( \pm SEM) Pearson correlation values $(r)$ between 0.01 and $0.1 \mathrm{~Hz}$ in $5 \mathrm{~min}$ time blocks. The effect of haloperidol injection $(0.25$, 0.5, I.0 mg/ $\mathrm{kg}$, i.p.) is shown for (d) $\operatorname{mPFC}(n=7)$ and $(e) \operatorname{mVS}(n=6)$ AUC measures extracted from the $\mathrm{O}_{2}$ response, where bars represent mean ( \pm SEM) AUC for the I-h period following haloperidol injection. ( $f$ ) Summary of coherence data showing the correlation of the whole frequency range $(0.0 \mathrm{I}-0 . \mathrm{I} \mathrm{Hz})$ for each treatment group in $5 \mathrm{~min}(300 \mathrm{~s})$ time bins $(n=8)$. Bars represent mean ( \pm SEM) Pearson correlation values $(r)$ between $0.0 \mathrm{l}$ and $0.1 \mathrm{~Hz}$ in 5 min time

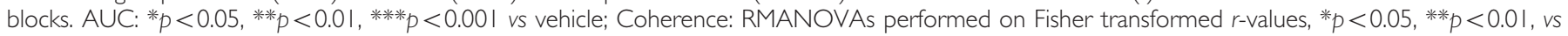
pre-injection baseline.

$(\mathrm{F}<1)$. For the Veh/Ket group, post hoc analyses confirmed significant increases in coherence at the $5-15$ min and $20-$ 25 min time points compared with the pre-injection baseline (all $p<0.05$ ), in agreement with findings from the ketamine dose response study. Compared with Veh/Ket, haloperidol pre-treatment caused a significant enhancement of ketamine-induced increase in regional $\left[\mathrm{O}_{2}\right]$ coherence following the $0.25 \mathrm{mg} / \mathrm{kg}$ dose at the $25-30 \mathrm{~min}$ time point, and the $0.5 \mathrm{mg} / \mathrm{kg}$ dose at the $10-20 \mathrm{~min}$ and $25-30 \mathrm{~min}$ time points.

\section{DISCUSSION}

This study demonstrates for the first time that it is possible to use in vivo $\mathrm{O}_{2}$ amperometry to simultaneously measure absolute regional $\mathrm{O}_{2}$ levels as well as regional coherence in low-frequency $\mathrm{O}_{2}$ signal fluctuations in the awake behaving rat. Using this approach, we observed a ketamine-induced signal whereby absolute $\mathrm{O}_{2}$ levels were dose-dependently increased in medial prefrontal cortical (mPFC) and ventral medial striatal (mVS) regions, together with an increased coherence of $\mathrm{O}_{2}$ signal between these regions, consistent with effects previously observed in humans (eg, De Simoni et al, 2013; Driesen et al, 2013). Administration of haloperidol and clozapine had dissociable effects on ketamine-induced increases in oxygenation and coherence, in a manner that also replicated what has been observed in humans (Doyle et al, 2013). Although the mechanistic relevance of these findings is yet to be determined, combining measurement of regional absolute tissue $\mathrm{O}_{2}$ levels with regional $\mathrm{O}_{2}$ coherence opens up a range of potential exploratory studies in rodents that might further define the predictive potential of these signals in humans.

Acute systemic administration of $(S)-(+)$-ketamine induced robust and sustained dose-related increases in tissue $\mathrm{O}_{2}$ levels in both the mPFC and mVS of freely moving rats. Ketamine $\mathrm{O}_{2}$ signals peaked rapidly in both brain sites, reflecting its known fast time course of action (Adams and Werner, 1997). The present results are in accordance with findings of past rodent glucose utilization studies (Duncan et al, 1998a, 1999; Miyamoto et al, 2000) and imaging studies (eg, Littlewood et al, 2006 and Chin et al, 2011) using ketamine and other NMDA receptor antagonists. Evidence of ketamine-induced neuronal activation also extends to neuroimaging markers in healthy humans (De Simoni et al, 2013; Deakin et al, 2008; Långsjö et al, 2003, 2004), suggesting an equivalent translational activation response of NMDA receptor antagonists across techniques and species. The present results also indicated increased mPFC-mVS inter-regional coherence of low-frequency oxygen oscillations following administration of $S-(+)$ ketamine. In human ketamine infusion studies, Driesen et al (2013) have shown increased global functional connectivity commensurate with psychotic symptoms in volunteers, and Anticevic et al (2012) demonstrated a disrupted reciprocal relationship between default mode and task-positive networks during the performance of a delayed working memory task. Although the present study did not incorporate behavioral assessment of animals, such studies are presently underway in our laboratories.

The effects of administration of clozapine and haloperidol were relatively small in contrast to the other findings 

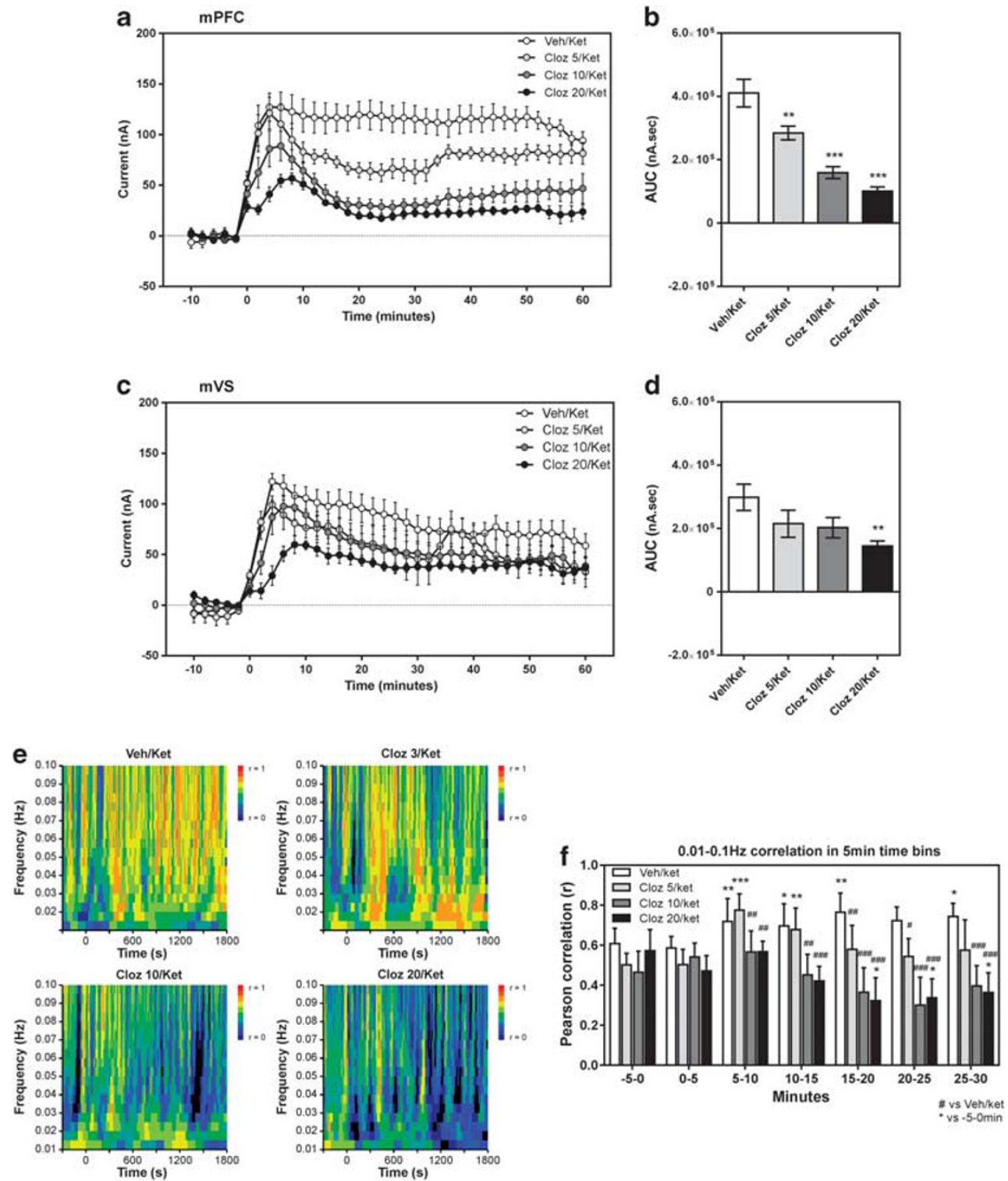

Figure 4 Clozapine-ketamine interaction study. (a) Temporal profile of changes in tissue $\mathrm{O}_{2}$ levels in mPFC ( $\left.n=6\right)$ and (c) mVSc ( $\left.n=5\right)$ following (s)-(+)-ketamine $\left(25 \mathrm{mg} / \mathrm{kg}\right.$, s.c.) injection in rats pre-treated with clozapine (5, 10,20 mg/kg, i.p.). Means ( \pm SEM) of normalized $\mathrm{O}_{2}$ currents averaged over 2-min time bins are shown over the I-h post-injection period. (b) mPFC and (d) mVS AUC measures extracted from the $\mathrm{O}_{2}$ response, where bars represent mean ( \pm SEM) AUC for the I-h period following ketamine injection. $* p<0.05$, $* * * 0.01$, **** $p<0.00$ I vs vehicle. (e) Coherograms for each treatment group showing the correlation value $(r)$ by color intensity at frequencies between $0.0 \mathrm{I}$ and $0.1 \mathrm{~Hz}$ ( $\mathrm{Y}$-axis) for $-300 \mathrm{~s}(5 \mathrm{~min}$ pre-injection) to $1800 \mathrm{~s}$ (30 min) post-ketamine injection on the $X$-axis. ( $f$ Summary of coherence data showing the correlation of the whole frequency range $(0.0 \mathrm{I}-0.1 \mathrm{~Hz})$ for each treatment group in $5 \mathrm{~min}(300 \mathrm{~s}$ ) time bins $(n=6)$. Bars represent mean ( \pm SEM) Pearson correlation values $(r)$ between $0.0 \mathrm{I}$ and $0.1 \mathrm{~Hz}$ in $5 \mathrm{~min}$ time blocks. RMANOVA performed on Fisher transformed $r$-values, ${ }^{*} p<0.05$, ${ }^{*} p<0.0$ I, ${ }^{*}{ }^{*} * p<0.00$ I vs pre-injection baseline; ${ }^{\#} p<0.05$, ${ }^{\# \#} p<0.0$ I, $\# \#$ \#\# $<0.001$ vs Veh group.

reported here, remaining broadly in line with previous studies (Duncan et al, 1998a, Cochran et al, 2002, Wotanis et al, 2003). Clozapine and haloperidol also had minimal effect on mPFC-mVS coherence when administered alone. Some recent imaging studies have also looked at the direct effect of various antipsychotics on resting-state fMRI in rodents (Gass et al, 2013) and schizophrenic patients (Sambataro et al, 2010; Bolding et al, 2012; Lui et al, 2010) with varying results. However, in terms of translational correspondence, this may be a particularly difficult literature to reconcile at present for several reasons. First in schizophrenic patients, baseline functional connectivity has been shown to be altered (Fox and Greicius, 2010) such that investigations of antipsychotics may be confounded by variation in regional coherence in different patients from the outset. An important next step for preclinical research will be to determine whether proposed animal models of schizophrenia can consistently recapitulate any of these baseline differences in patients, as these models would then represent a more meaningful platform from which to study drug effects. Second, it is not clear at present how uniform and temporally stable such changes in functional connectivity are across the schizophrenic syndrome as a whole, and which resting state 

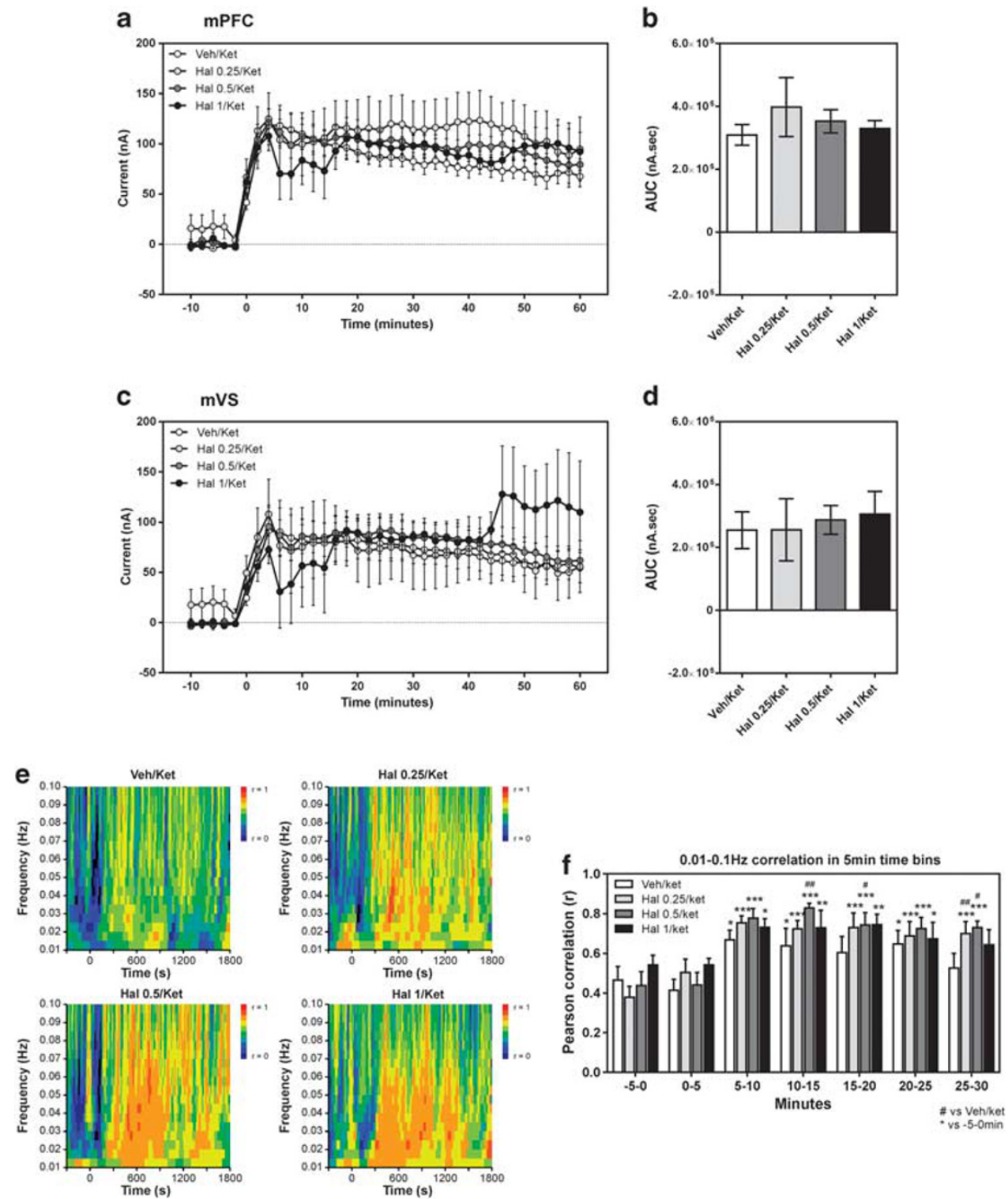

Figure 5 Haloperidol-ketamine interaction study. (a) Temporal profile of changes in tissue $\mathrm{O}_{2}$ levels in the mPFC $(n=6)$ and $(c)$ the mVSc $(n=5)$ following S- $(+)$-ketamine $\left(25 \mathrm{mg} / \mathrm{kg}\right.$, s.c.) injection in rats pre-treated with haloperidol $\left(0.25,0.5,1.0 \mathrm{mg} / \mathrm{kg}\right.$, i.p.). Means $( \pm \mathrm{SEM})$ of normalized $\mathrm{O}_{2}$ currents averaged over 2-min time bins are shown over the I-h post-injection period. (b) mPFC and (d) mVS AUC measures extracted from the $\mathrm{O}_{2}$ response, where bars represent mean $\left( \pm\right.$ SEM) AUC for the I-h period following ketamine injection. ${ }^{*} p<0.05, * * p<0.0$ I, **** $p<0.00$ I vs vehicle. (e) Coherograms for each treatment group showing the correlation value $(r)$ by color intensity at frequencies between $0.0 \mathrm{l}$ and $0.1 \mathrm{~Hz}$ (Y-axis) for - $300 \mathrm{~s}$ (5 min pre-injection) to $1800 \mathrm{~s}$ (30 min) post-ketamine injection on the $X$-axis. ( $f$ ) Summary of coherence data showing the correlation of the whole frequency range $(0.0 \mathrm{I}-0.1 \mathrm{~Hz})$ for each treatment group in $5 \mathrm{~min}(300 \mathrm{~s})$ time bins $(n=7)$. Bars represent mean $( \pm \mathrm{SEM})$ Pearson correlation values $(r)$ between $0.0 \mathrm{I}$ and $0.1 \mathrm{~Hz}$ in 5 min time blocks. RMANOVA performed on Fisher transformed $r$-values, ${ }^{*} p<0.05$, ${ }^{*} * p<0.01$, $* * * * * 0.00$ I vs pre-injection baseline; ${ }^{\#} p<0.05$,

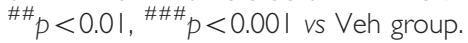

network changes (and hence nodes to evaluate in animal studies) are the most relevant to specific symptoms and patient outcome.

Compared with their rather meager effects on baseline measurements in rats, clozapine, and haloperidol had marked and differential effects on regional $\left[\mathrm{O}_{2}\right]$ and mPFC-mVS coherence induced by ketamine. Most notably, clozapine $(5-20 \mathrm{mg} / \mathrm{kg}$ ) produced significant dose-dependent suppression of ketamine-induced increases in both regions, and also attenuated ketamine-induced increases in mPFC$\mathrm{mVS}$ coherence. In contrast, haloperidol $(0.25-1.0 \mathrm{mg} / \mathrm{kg})$ did not significantly modulate $\left[\mathrm{O}_{2}\right]$ following ketamine administration, and potentiated mPFC-mVS coherence over and above the increase induced by ketamine alone. The regional $\left[\mathrm{O}_{2}\right]$ observations presented here are in line with previous findings using other techniques. For instance, Duncan et al (1998a) showed in rats that increases in 2-DG uptake induced by $30 \mathrm{mg} / \mathrm{kg}$ of ketamine were normalized by clozapine $(5-10 \mathrm{mg} / \mathrm{kg})$ in all brain regions studied, whereas a $0.5 \mathrm{mg} / \mathrm{kg}$ dose of haloperidol potentiated ketamineinduced activation of 2-DG uptake. A phMRI study in anesthetized rats (Gozzi et al, 2008) has also shown that acute 
administration of PCP $(0.5 \mathrm{mg} / \mathrm{kg}$, i.v. $)$ produced robust and sustained increases in relative cerebral blood volume (rCBV) in discrete cortico-limbo-thalamic regions, and that clozapine $(5 \mathrm{mg} / \mathrm{kg})$ completely suppressed PCP-induced $\mathrm{rCBV}$ responses in the thalamus and less so in cortical and hippocampal structures, whereas raclopride $(0.3 \mathrm{mg} / \mathrm{kg})$, a dopamine $\mathrm{D}_{2}$ antagonist similar to haloperidol, did not affect the PCP-induced increases in rCBV. This study also demonstrated no effects of clozapine or raclopride per se on $\mathrm{rCBV}$, broadly consistent with our present findings. More recently, a phMRI study in healthy human volunteers described attentuation of the BOLD signal increase induced by ketamine challenge by the atypical antipsychotic risperidone and the anticonvulsant lamotrigine (Doyle et al, 2013).

Importantly, differential effects on $\mathrm{mPFC}-\mathrm{mVS}$ coherence were observed, where clozapine attenuated ketamineinduced increases in $\mathrm{mPFC}-\mathrm{mVS}$ coherence, but haloperidol enhanced this coherence. To date, there are no known rsfMRI studies describing the effect of antipsychotics on an NMDA receptor antagonist-induced modulation of functional connectivity-this will be a crucial translational comparison to be conducted. Future preclinical $\mathrm{O}_{2}$ amperometry work also needs to measure from various other nodes in resting state networks, first to more precisely define the extent to which these networks are homologous to those described in humans, but also to show that this indeed is a phenomenon specific to restricted nodes and not simply a global, non-specific effect. As physiological changes such as heart rate or blood pressure were not recorded in this study, their contribution to coherence levels cannot be determined. However, unpublished data from this lab shows that different combinations of brain regions in the same animal show different levels of coherence, suggesting that high coherence at rest is not a global response caused by a physiological artifact of this technique. The simultaneous measurement of other physiological parameters and behaviors such as locomotor activity will also help rule out the possibility of artifactual confound of functional connectivity measures. Although we have shown a clear differential effect of clozapine and haloperidol on ketamine-induced changes in activation and functional connectivity, the mechanistic interpretation of this effect needs to be further investigated. Studies that compare the hemodynamic response to direct measures of neuronal activity such as EEG/LFP recordings under the influence of this pharmacology, as well as measuring behavioral responses, would help elucidate the functional significance of these findings.

It is undoubtedly premature to assign a functional significance to the differences in regional amperometric $\mathrm{O}_{2}$ levels and inter-regional coherence effects, yet the present results demonstrate differential responses of typical and atypical antipsychotics on NMDA antagonist-induced brain activation and functional connectivity. These results fit well with existing literature on phMRI and rsfMRI responses described already, and lay the foundation for experiments analogous to functional connectivity imaging methods to be conducted in awake, behaving animals. This holds great promise for the development of a novel translational bridging technology to better define crossspecies biomarkers for drug research and functional assays for neuroscience research in general.

\section{FUNDING AND DISCLOSURE}

JL, MWC, JF, JH, AJS, MT and GG are employees of Eli Lilly and Co. Ltd. KI was financially supported by Eli Lilly and Co. Ltd. The remaining authors declare no conflict of interest.

\section{ACKNOWLEDGEMENTS}

JPL acknowledges the financial support of NUI Maynooth, Enterprise Ireland (CFTD/2008/107), Science Foundation Ireland (03/IN3/B376S), and Eli Lilly and Co. Limited. KI acknowledges the support of NUI Maynooth.

\section{REFERENCES}

Adams HA, Werner C (1997). From the racemate to the eutomer: (S)-ketamine. Renaissance of a substance? Anaesthesist 46: 1026-1042.

Anis NA, Berry SC, Burton NR, Lodge D (1983). The dissociative anaesthetics, ketamine and phencyclidine, selectively reduce excitation of central mammalian neurones by $\mathrm{N}$-methylaspartate. Br J Pharmac 79: 565-575.

Anticevic A, Gancsos M, Murray JD, Repovs G, Driesen NR, Ennis DJ et al (2012). NMDA receptor function in large-scale anticorrelated neural systems with implications for cognition and schizophrenia. PNAS 109: 16720-16725.

Biswal B, Yetkin FZ, Haughton VM, Hyde JS (1995). Functional connectivity in the motor cortex of resting human brain using echo-planar MRI. Magn Reson Med 34: 537-541.

Bolding MS, White DM, Hadley JA, Weiler M, Holcomb HH, Lahti AC (2012). Antipsychotic drugs alter functional connectivity between the medial frontal cortex, hippocampus, and nucleus accumbens as measured by H215O PET. Front Psychiatry 3: 105.

Bolger FB, McHugh SB, Bennett R, Li J, Ishiwari K, Francois J et al (2011). Characterisation of carbon paste electrodes for real-time amperometric monitoring of brain tissue oxygen. J Neurosci Methods 195: 135-142.

Bourdillon C, Thomas V, Thomas D (1982). Electrochemical study of D-glucose oxidase autoinactivation. Enzyme Microb Technol 4: $175-180$.

Chin CL, Upadhyay J, Marek GJ, Baker SJ, Zhang M, Mezler M et al (2011). Awake rat pharmacological magnetic resonance imaging as a translational pharmacodynamic biomarker: metabotropic glutamate $2 / 3$ agonist modulation of ketamine-induced blood oxygenation level dependence signals. J Pharmacol Exp Ther 336: 709-715.

Cochran SM, McKerchar CE, Morris BJ, Pratt JA (2002). Induction of differential patterns of local cerebral glucose metabolism and immediate-early genes by acute clozapine and haloperidol. Neuropharmacology 43: 394-407.

Deakin JF, Lees J, McKie S, Hallak JE, Williams SR, Dursun SM (2008). Glutamate and the neural basis of the subjective effects of ketamine: a pharmaco-magnetic resonance imaging study. Arch Gen Psychiatry 65: 154-164.

De Simoni S, Schwarz AJ, O’Daly OG, Marquand AF, Brittain C, Gonzales C et al (2013). Test-retest reliability of the BOLD pharmacological MRI response to ketamine in healthy volunteers. Neuroimage 64: 75-90.

Doyle OM, De Simoni S, Schwarz AJ, Brittain C, O’Daly OG, Williams SC et al (2013). Quantifying the attenuation of the ketamine pharmacological magnetic resonance imaging response in humans: a validation using antipsychotic and glutamatergic agents. J Pharmacol Exp Ther 345: 151-160.

Driesen NR, McCarthy G, Bhagwagar Z, Bloch M, Calhoun V, D'Souza DC et al (2013). Relationship of resting brain 
hyperconnectivity and schizophrenia-like symptoms produced by the NMDA receptor antagonist ketamine in humans. Mol Psychiatry 18: 1199-1204.

Duncan GE, Leipzig JN, Mailman RB, Lieberman JA (1998a). Differential effects of clozapine and haloperidol on ketamineinduced brain metabolic activation. Brain Res 812: 65-75.

Duncan GE, Moy SS, Knapp DJ, Mueller RA, Breese GR (1998b). Metabolic mapping of the rat brain after subanesthetic doses of ketamine: potential relevance to schizophrenia. Brain Res 787: 181-190.

Duncan GE, Miyamoto S, Leipzig JN, Lieberman JA (1999). Comparison of brain metabolic activity patterns induced by ketamine, MK-801 and amphetamine in rats: support for NMDA receptor involvement in responses to subanesthetic dose of ketamine. Brain Res 843: 171-183.

Ferris CF, Smerkers B, Kulkarni P, Caffrey M, Afacan O, Toddes S et al (2011). Functional magnetic resonance imaging in awake animals. Rev Neurosci 22: 665-674.

Foster TH, Hartley DF, Nichols MG, Hilf R (1993). Fluence rate effects in photodynamic therapy of multicell tumor spheroids. Cancer Res 53: 1249-1254.

Fox MD, Greicius M (2010). Clinical applications of resting state functional connectivity. Front Syst Neurosci 4: 19.

Fox MD, Raichle ME (2007). Spontaneous fluctuations in brain activity observed with functional magnetic resonance imaging. Nat Rev Neurosci 8: 700-711.

Francois J, Conway MW, Lowry JP, Tricklebank MD, Gilmour G (2012). Changes in reward-related signals in the rat nucleus accumbens measured by in vivo oxygen amperometry are consistent with fMRI BOLD responses in man. Neuroimage 60: 2169-2181.

Gass N, Schwarz AJ, Sartorius A, Cleppien D, Zheng L, Schenker E et al (2013). Haloperidol modulates mid-brain-prefrontal functional connectivity in the rat brain. Eur Neuropsychopharmacol 23: $1310-1319$.

Gozzi A, Large CH, Schwarz A, Bertani S, Crestan V, Bifone A (2008). Differential effects of antipsychotic and glutamatergic agents on the phMRI response to phencyclidine. Neuropsychopharmacology 33: 1690-1703.

Hitchman ML (1978). Measurement of Dissolved Oxygen, Vol. 49 (Krieger Publishing Company).

Howe WM, Berry AS, Francois J, Gilmour G, Carp JM, Tricklebank $M$ et al (2013). Prefrontal cholinergic mechanisms instigating shifts from monitoring for cues to cue-guided performance: converging electrochemical and fMRI evidence from rats and humans. J Neurosci 33: 8742-8752.

Krystal JH, Karper LP, Seibyl JP, Freeman GK, Delaney R, Bremner JD et al (1994). Subanesthetic effects of the noncompetitive NMDA antagonist, ketamine, in humans. Psychotomimetic, perceptual, cognitive, and neuroendocrine responses. Arch Gen Psychiatry 51: 199-214.

Lahti AC, Koffel B, LaPorte D, Tamminga CA (1995). Subanesthetic doses of ketamine stimulate psychosis in schizophrenia. Neurophychopharmacology 13: 9-19.

Långsjö JW, Kaisti KK, Aalto S, Hinkka S, Aantaa R, Oikonen V et al (2003). Effects of subanesthetic doses of ketamine on regional cerebral blood flow, oxygen consumption, and blood volume in humans. Anesthesiology 99: 614-623.

Långsjö JW, Salmi E, Kaisti KK, Aalto S, Hinkka S, Aantaa R et al (2004). Effects of subanesthetic ketamine on regional cerebral glucose metabolism in humans. Anesthesiology 100: 1065-1071.
Li J, Bravo DS, Upton AL, Gilmour G, Tricklebank MD, Fillenz M et al (2011). Close temporal coupling of neuronal activity and tissue oxygen responses in rodent whisker barrel cortex. Eur J Neurosci 34: 1983-1996.

Littlewood CL, Jones N, O'Neill MJ, Mitchell SN, Tricklebank M, Williams SC (2006). Mapping the central effects of ketamine in the rat using pharmacological MRI. Psychopharmacology (Berl) 186: $64-81$.

Lodge D, Johnson KM (1990). Noncompetitive excitatory amino acid receptor antagonists. Trends Pharmacol Sci 11: 81-86.

Lowry JP, Boutelle MG, Fillenz M (1997). Measurement of brain tissue oxygen at a carbon past electrode can serve as an index of increases in regional cerebral blood flow. J Neurosci Methods 71: 177-182.

Lowry JP, Boutelle MG, O’Neill RD, Fillenz M (1996). Characterization of carbon paste electrodes in vitro for simultaneous amperometric measurement of changes in oxygen and ascorbic acid concentrations in vivo. Analyst 121: 761-766.

Lowry JP, Griffin K, McHugh SB, Lowe AS, Tricklebank M, Sibson NR (2010). Real-time electrochemical monitoring of brain tissue oxygen: a surrogate for functional magnetic resonance imaging in rodents. Neuroimage 52: 549-555.

Lui S, Li T, Deng W, Jiang L, Wu Q, Tang H et al (2010). Shortterm effects of antipsychotic treatment on cerebral function in drug-naive first-episode schizophrenia revealed by "resting state" functional magnetic resonance imaging. Arch. Gen Psychiatry 67: 783-792.

Malhotra AK, Pinals DA, Weingartner H, Sirocco K, Missar CD, Pickar D et al (1996). NMDA receptor function and human cognition: the effects of ketamine in healthy volunteers. Neuropsychopharmacology 14: 301-307.

McHugh SB, Marques-Smith A, Li J, Rawlins JN, Lowry J, Conway $M$ et al (2013). Hemodynamic responses in amygdala and hippocampus distinguish between aversive and neutral cues during Pavlovian fear conditioning in behaving rats. Eur $J$ Neurosci 37: 498-507.

Moghaddam B, Adams B, Verma A, Daly D (1997). Activation of glutamatergic neurotransmission by ketamine: a novel step in the pathway from NMDA receptor blockade to dopaminergic and cognitive disruptions associated with the prefrontal cortex. J Neurosci 17: 2921-2927.

Miyamoto S, Leipzig JN, Lieberman JA, Duncan GE (2000). Effects of ketamine, MK-801, and amphetamine on regional brain 2deoxyglucose uptake in freely moving mice. Neuropsychopharmacology 22: 400-412.

O’Neill RD, Grunewald RA, Fillenz M, Albery WJ (1982). Linear sweep voltammetry with carbon paste electrodes in the rat striatum. Neuroscience 7: 1945-1954.

Paxinos G, Watson C (2009). The Rat Brain in Stereotaxic Coordinates. 6th edn, Elsevier.

Sambataro F, Blasi G, Fazio L, Caforio G, Taurisano P, Romano R et al (2010). Treatment with olanzapine is associated with modulation of the default mode network in patients with Schizophrenia. Neuropsychopharmacology 35: 904-912.

Wotanis J, Hanak SE, Wettstein JG, Black MD (2003). Comparative analysis of acute and chronic administration of haloperidol and clozapine using [3H] 2-deoxyglucose metabolic mapping. Schizophr Res 61: 195-205.

Zhu Y, Gao B, Hua J, Liu W, Deng Y, Zhang L et al (2013). Effects of methylphenidate on resting-state brain activity in normal adults: an fMRI study. Neurosci Bull 29: 16-27. 